\title{
ROTURA ESPONTÂNEA DE ANEURISMA DA ARTÉRIA CÓLICA MÉDIA
}

\author{
Spontaneous rupture of aneurysm of the middle colic artery \\ Samuel Moraes IELO, Rodrigo Gibin JALDIN, Laura Siqueira da COSTA, \\ Rogério Massaru WATANABE, Rogério SAAD-HOSSNE, Maria Aparecida C. de Arruda HENRY
}

ABCDDV/681

Ielo SM, Jaldin RG, Costa LS, Watanabe RG, Saad-Hossne R, Henry MACA. Rotura espontânea de aneurisma da artéria cólica média. ABCD Arq Bras Cir Dig 2009;22(4):237-9

RESUMO - Introdução - Os aneurismas que envolvem os ramos principais da artéria mesentérica superior são incomuns e entre eles encontra-se uma situação rara: o aneurisma da artéria cólica média. Embora pouco frequente, é um importante grupo de doença vascular, pois boa parte destes é diagnosticada em emergências cirúrgicas. Relato do caso - Descreve-se um caso de aneurisma roto de artéria cólica média em paciente jovem e hígida do sexo feminino, diagnosticado no intra-operatório de laparotomia exploradora frente a um quadro de dor abdominal e diarréia que evoluiu subitamente para abdome agudo e choque. Realizou-se a ligadura desta artéria com controle efetivo da hemorragia, sem comprometimento identificável macroscopicamente de irrigação ou viabilidade do cólon transverso ou demais segmentos colônicos. Apesar do sucesso do tratamento cirúrgico, a paciente evolui para óbito no $12^{\circ}$. dia pós-operatório por complicações hemorrágicas do sistema nervoso central. Conclusão - A provável causa do aneurisma da artéria cólica média envolve a mediólise segmentar idiopática na qual se observa processo degenerativo da camada média. DESCRITORES - Aneurisma.

\section{INTRODUÇÃO}

Os aneurismas viscerais consistem em dilatações segmentares dos ramos viscerais da aorta abdominal ${ }^{11}$ e embora pouco frequentes, representam um importante grupo de doenças vasculares, pois $25 \%$ deles são diagnosticados em emergências cirúrgicas ${ }^{8}$. Os aneurismas das artérias cólicas, juntamente com os das artérias jejunal e ileal correspondem a $3 \%$ dos aneurismas das artérias esplâncnicas e a maioria dos casos descritos envolvem rotura, complicação esta que cursa com risco estimado em $30 \%$ dos casos e $20 \%$ de mortalidade operatória ${ }^{1,5,8}$. Em geral, a rotura ocorre para dentro do trato gastrointestinal, sendo rara para a cavidade abdominal ${ }^{1,8}$. Este artigo relata um caso de aneurisma roto de artéria cólica média em paciente jovem e hígida do sexo feminino, diagnosticado no intra-operatório de laparotomia exploradora frente a um quadro de abdome agudo e choque.

\section{RELATO DO CASO}

Mulher de 45 anos, procedente de Botucatu -SP, sem qualquer antecedente mórbido, dá entrada no pronto-socorro por queixa de náusea, vômitos, diarréia e dor abdominal há $48 \mathrm{~h}$, iniciada após a ingestão de um salgado. Ao exame físico de entrada, apresentava-se em regular estado geral, corada, desidratada, pressão arterial de 110x80 mmHg, frequência

Trabalho realizado no Hospital das Clínicas da Faculdade de Medicina de Botucatu - Departamento de Cirurgia e Ortopedia - Universidade Estadual Paulista (UNESP), Botucatu, SP, Brasil.

Correspondência: Maria Aparecida C. de Arruda Henry, e-mail: rhenry@ibb.unesp.br / rgibin@uol.com.br cardíaca de 70 bpm e respiratória de $20 \mathrm{mrpm}$. Ao exame abdominal, observava-se dor à palpação do epigástrio, apenas. Solicitados exames laboratoriais foi evidenciado $\mathrm{Hb}=12,4 ; \mathrm{Ht}=34,9 \% ; \mathrm{GB}=13.700$, sem desvio à esquerda e eletrólitos dentro dos valores de normalidade. Sob a hipótese diagnóstica de gastroenterocolite aguda (intoxicação alimentar ou viral), recebeu hidratação endovenosa. Apesar da conduta instituída, a paciente obteve apenas melhora parcial, sendo mantida sob observação. Após 6 h da admissão, evoluiu com queda do nível de consciência e persistência da dor abdominal e diarréia. A reavaliação dos sinais vitais evidenciou $\mathrm{PA}=90 \times 60 \mathrm{mmHg} ; \mathrm{Fc}=\mathrm{P}=120 \mathrm{bpm}$; desidratada; descorada 4+/4+; abdome em tábua com ruídos hidroaéreos reduzidos em frequência e intensidade. Foi indicada laparotomia exploradora de emergência, a qual evidenciou sangue em grande quantidade na cavidade abdominal (Figura 1) com volume estimado de 1,5 litro e hematoma de $15 \mathrm{~cm}$ identificado na topografia do mesocólon transverso, ocupando toda a retrocavidade. Após aspiração do sangue e remoção mecânica dos coágulos, observou-se vaso aneurismático de $12 \mathrm{~mm} \times 10 \mathrm{~mm}$ de diâmetro, com sangramento ativo e pulsátil, sendo ele identificado como a artéria cólica média (Figura 2). Realizou-se a ligadura desta artéria com controle efetivo da hemorragia, sem comprometimento identificável macroscopicamente de irrigação ou viabilidade do cólon transverso ou demais segmentos colônicos. Considerando intra-operatório e pós-operatório imediato, a paciente recebeu nove unidades de concentrado de hemácias, sete de plasma fresco congelado e seis de crioprecipitado. Após $12 \mathrm{~h}$ de pós-operatório, ainda sob cuidados intensivos em unidade especializada, a paciente apresentou instabilidade 


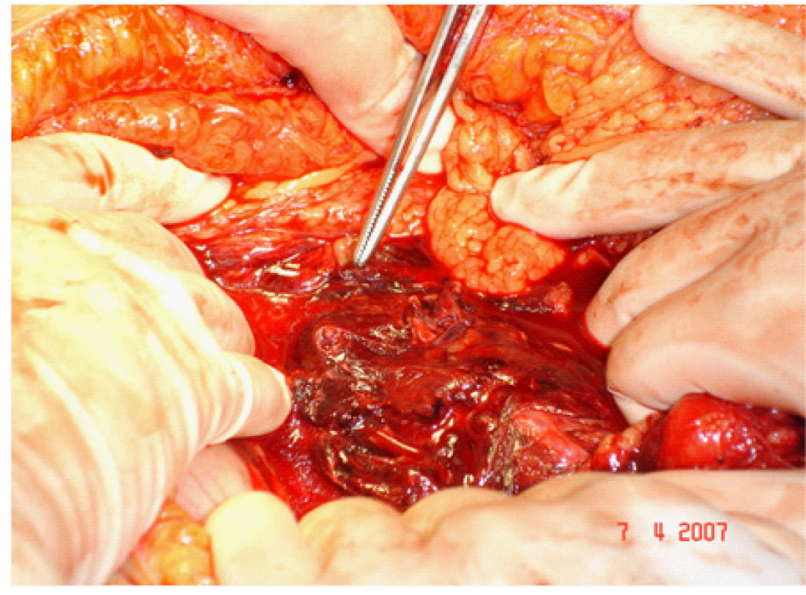

FIGURA 1 - Imagem do campo cirúrgico da laparotomia exploradora podendo-se observar grande hematoma na topografia do mesocólon transverso

hemodinâmica e sangramento pelo cateter venoso central, incisão cirúrgica e dreno sentinela. Aventada a hipótese "coágulo retido" e optado por nova abordagem cirúrgica para revisão de hemostasia que evidenciou grande quantidade de coágulos e de líquido sero-hemático na cavidade (aproximadamente $1000 \mathrm{~mL}$ ) apesar da não identificação de qualquer foco de sangramento ativo e da perfeita viabilidade das alças intestinais. A paciente apresentou boa evolução pós-operatória, mantendo-se estável com níveis mínimos e decrescentes de droga vasoativa saindo rapidamente do íleo paralítico pós-operatório, o que permitiu evolução progressiva da dieta. Recebeu alta hospitalar no $10^{\circ}$ dia de pós-operatório aceitando dieta geral com parâmetros laboratoriais e de exame físico normais.

Decorridos dois dias da alta hospitalar $\left(12^{\circ}\right.$ da operação), ela que outrora estava assintomática e em convalescença, apresentou quadro convulsivo caracterizado por crise tônico-clônica generalizada e insuficiência respiratória aguda necessitando suporte ventilatório invasivo. Para investigação do quadro, foi realizada tomografia computadorizada de crânio mostrando imagem compatível com hemorragia subaracnoídea com inundação ventricular correspondente ao grau IV da classificação de Fischer, quadro este que inviabilizou conduta neurocirúrgica invasiva. A paciente evoluiu ao óbito após dois dias.

\section{DISCUSSÃO}

Os aneurismas das artérias viscerais são raros e envolvem mais comumente a artéria esplênica ${ }^{1,5,7,8,9,11}$. Acometem a artéria mesentérica superior e seus ramos principais em, respectivamente, $5,5 \%$ e $3 \%$ dos casos envolvendo artérias esplâncnicas ${ }^{1,8,9}$. As causas mais frequentes destes aneurismas são aterosclerose, angiodisplasia, arterites e infecção5-8. Slavin e col propuseram como causa a mediólise segmentar idiopática na qual se observa processo degenerativo da camada média (degeneração medial ou mediólise), caracterizado pela fragmentação do tecido elástico com formação de pequenos espaços preenchidos por tecido colágeno $0^{2,12,13,14}$.

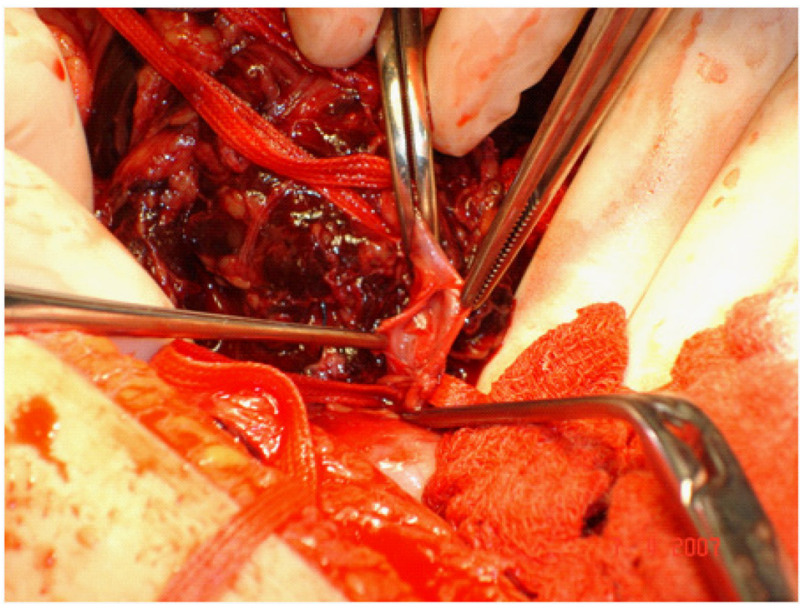

FIGURA 2 - Imagem do campo cirúrgico observando-se a artéria cólica média clampeada com destaque para o local da rotura

Esta alteração também é comumente encontrada nas dissecções agudas de aorta e nos aneurismas rotos da aorta abdominal ${ }^{4}$. Os aneurismas que acometem a artéria cólica média geralmente são assintomáticos, mas tornam-se graves em situação de rotura, trombose e embolização distal ${ }^{2,8,9}$. São pequenos, de aproximadamente $1,5 \mathrm{~cm}$ de diâmetro, e são achados incidentais em arteriografias ${ }^{3,10}$.

Em concordância com os sintomas descritos neste caso, os aneurismas da artéria cólica média rotos podem apresentar-se inicialmente por desconforto abdominal e diarréia por alguns dias precedendo quadro de dor abdominal intensa e súbita. Tais sintomas resultam de efeito de massa decorrente de hematoma rapidamente expansível comprimindo as estruturas adjacentes ou ainda por alterações intestinais isquêmicas causadas pela hipoperfusão ${ }^{2}$. Quando rompem efetivamente, apresentam-se por hematomas mesentéricos ou sangramento gastrointestinal maciço. O diagnóstico inicial em situação de emergência depende da suspeição e provavelmente a tomografia computadorizada de abdome é o melhor método de imagem para identificação de aneurismas intra-abominais $\operatorname{rotos}^{3,10}$, porém o diagnóstico definitivo dá-se por angiogra$f i a^{15}$. No caso relatado, entretanto, não foi possível a realização de qualquer método diagnóstico pré-operatório visto que a paciente apresentava-se hemodinamicamente instável. O tratamento cirúrgico da rotura, apesar da mortalidade de $20 \%$, pode ser realizado com sucesso, como descrito neste caso e em relatos anteriores. Consiste em aneurismectomia, ligadura ou ressecções intestinais segmentares ${ }^{7,9}$. Atualmente, descrevem-se tratamentos endovasculares menos invasivos caracterizados por cateterização superseletiva e embolização precisa ${ }^{9}$. Entretanto, os riscos de infarto intestinal, perfuração e estenose intestinal limitam a ampla utilização da embolização como tratamento dos aneurismas das artérias viscerais ${ }^{6,9}$.

\section{CONCLUSÃO}

A provável causa do aneurisma da artéria cólica média envolve a mediólise segmentar idiopática na qual se observa processo degenerativo da camada média. 
Ielo SM, Jaldin RG, Costa LS, Watanabe RG, Saad-Hossne R, Henry MACA. Spontaneous rupture of aneurysm of the middle colic artery. ABCD Arq Bras Cir Dig 2009;22(4):237-9

ABSTRACT - Background - Aneurysms of the superior mesenteric artery branches are uncommon, even among them colic artery aneurysms are rare. These aneurysms are usually asymptomatic, but rupture, thrombosis and distal embolization have been reported like complications. Case report - A case of a 45-year-old female patient with spontaneous rupture of an aneurysm of middle colic artery, which was diagnosed at exploratory laparotomy, is presented. The patient suddenly developed severe abdominal pain and shock. The aneurysm was completely resected at surgery. Therefore the bleeding could be successfully managed with surgery, but the patient died with post-operative complications. Conclusion - In this case, the aneurysm of middle colic artery was probably resulting from idiopatic segmental mediolysis.

HEADINGS - Aneurysm

\section{REFERÊNCIAS}

1. Brito CJ. Aneurismas Periféricos. In: Maffei FHA, Lastória S, Yoshida WB, Rollo HA (eds). Doenças Vasculares Periféricas, Segunda Ed. Medsi, 1995, cap 33, p. 557-576.

2. Chino O, Kijima H, Shibuya M, Yamamoto S, Kashiwagi H, Kondo Y, Makuuchi H. A Case Report: Spontaneous rupture of dissecting aneurysm of the middle colic artery. Tokai J Exp Cin Med, 2004, 29(4): 155-158.

3. Dravid VS, Sullivan KL, Carter WB, Carabasi RA, Needleman L. Role of selective arteriography in the diagnosis of a ruptured middle colic artery aneurysm. Cardiovasc Intervent Radiol, 1994, 17:167-169.

4. Gutierrez PS, Reis MM, Higuchi ML, Aiello VD, Stolf NAG, Lopes EA. Distribuition of hialuranan and dermatan/chondroitin sulfate proteoglicans in human aortic dissecation. Connective Tissue Res. 1998; 37(3-4): 151-161.

5. Izukawa NM. Aneurismas das artérias viscerais. In: Puech-Leão P, Kauffman P (eds). Aneurismas Arteriais. Fundo editorial BYK, São Paulo, 1998, cap 22, p. 233.

6. Ku A, Kadir S. Embolization of a mesenteric artery aneurysm: Case report. Cardiovasc Intervent Radiol, 1990, 13:91-92.

7. McNamara MF, Griska LB. Superior mesenteric artery branch aneurysm. Surgery, 1980, 88:625-630.

8. Miranda Jr F. Aneurismas viscerais e periféricos. In: Pitta GBB, Castro AA,
Burihan E (eds). Angiologia e Cirurgia Vascular: guia ilustrado. UNICSAL/ ECMAL \& LAVA, Maceió, 2003.

9. Naito A, Toyota N, Ito K. Embolization of a Ruptured Middle Colic Artery Aneurysm. Cardiovasc Intervent Radiol, 1995, 18:56-58.

10. Reuter SR, Redman HC, Cho KJ. Gastrointestinal angiography, 3rd Ed. Saunders \& Co, Philadelphia, 1986, p. 97-104.

11. Sandri JL, Souza Netto JM. Aneurismas das artérias viscerais. In: Bonamigo TP, Von Ristow A (eds). Aneurismas. Dilivros, Rio de Janeiro, 2000, cap 25, p. 230-243.

12. Slavin RE, Calferty L, Carrwright J. Segmental mediolytic arterits: a clinicopathologic and ultrastructural study of two cases. Am J Surg Pathol, 1989, 13:558-568.

13. Slavin RE, Gonzalez-Vitale JC. Segmental mediolytic arteritis: a clinical pathologic study. Lab Invest, 1976, 35: 23-29.

14. Slavin RE, Saeki R, Bhagawan B, et al. Segmental mediolytic arterits: a precursor to fibromuscular dysplasia? Med Pathol, 1995, 287-294.

15. Wachman J, Schoen RE. Intermitent abdominal pain with aneurysm of the middle colic artery. Am J Gastroenterol, 1995, 90:499-501.

Fonte de financiamento: não há Conflito de interesse: não há Recebido para publicação:10/08/2008 Aceito para publicação: 30/09/2008 